\title{
Human-computer interaction: A preliminary social psychological analysis
}

\author{
LEO R. QUINTANAR, CHARLES R. CROWELL, and JOHN B. PRYOR \\ University of Notre Dame, Notre Dame, Indiana 46556 \\ and \\ JOHN ADAMOPOULOS \\ Indiana University, South Bend, Indiana 46615
}

\begin{abstract}
Considering an interactive computer as a social stimulus suggests that contemporary social psychological theories can contribute to the prediction of user attitude and performance. In order to assist in the systematic exploration of this possibility, we developed DIALOGUE, an on-line system to investigate the effects of varying the computer's responses to the user. This system involves a presentation program that displays the computer's responses, performs the pacing of video information, and collects a variety of measurements, including the user's response time and the number of correct/incorrect user responses. DIALOGUE also includes a data manager that allows the experimenter to examine or modify the information collected by the presentation program. Utilizing DIALOGUE, we conducted a preliminary investigation of one aspect of human-computer interaction, the effects of varying the degree of human-like responses exhibited by the computer. Results suggest that (1) there are underlying dimensions of judgment involving perception of interactive computers, (2) a manipulation of human-like computer responses is reflected primarily in certain of these dimensions, and (3) such a manipulation influences user performance and feelings of responsibility. Factors related to the implementation of DIALOGUE are considered, and its potential for investigations of a variety of human-computer interactions is discussed.
\end{abstract}

The frequency and duration of human-computer interactions has escalated, as is demonstrated by the diversity of interactive recreational and problem solving software, as well as by the growing popularity of computer-assisted education. Commensurate with these developments has been an expanded research interest in the impact of the computer upon user attitude and performance (e.g., Shneiderman, 1980; Smith \& Green, 1980). One factor that has received relatively little attention is the importance of the stimulus properties of the interactive computer's responses to the user. Certain developments in the field of social psychology may be especially useful in understanding the effects of varying such properties.

Social psychology is defined classically as the study of "how the thought, feeling, and behavior of individ-

The authors wish to express their appreciation to Alice Gallagher and Joan McCurdy for assistance during collection and reduction of the experimental data and to James Wilmes of the Computing Center staff at the University of Notre Dame for his helpful assistance with portions of the software. This paper was supported in part by a grant from the Notre Dame Graduate Student Union. Requests for reprints or inquiries about software should be directed to Leo R. Quintanar or Charles R. Crowell, Department of Psychology, University of Notre Dame, Notre Dame, Indiana 46556. uals are influenced by the actual, implied, or imagined presence of others" (Allport, 1968). In certain ways, the interactive experience with computers can be subsumed under the description of "implied or imagined presence of others." For example, it has been well documented that under some circumstances users will ascribe human-like qualities to an interactive computer (Weizenbaum, 1976). Accordingly, it may be possible, at least under some conditions, to view the interactive computer as a social stimulus in the human-computer interaction process. From this perspective, a fuller analysis than presently exists of the social psychological impact of the interactive computer becomes imperative. Conceivably, contemporary social theories may lead to a greater understanding of the manner in which a user may be influenced through interactions with a computer.

Recently, we have begun to explore such a possibility. The first step was to develop a paradigm in which the interactive computer's response to the user could be easily manipulated and studied. The purpose of this paper is to describe the DIALOGUE system that has emerged from our efforts and the results of an initial experiment using this system. The research suggests that the user's attitude and performance are affected by the degree of human-like responses exhibited by an interactive computer. 


\section{DIALOGUE SYSTEM}

The DIALOGUE system permits easy experimental manipulations of the stimulus properties of the computer's responses to the user. These manipulations are accomplished through variation in the type of statements, responses, and pacing that the computer displays to the user throughout an interactive sequence. DIALOGUE not only permits such variation but also can serve to administer quizzes and to record various measurements of a subject's performance that are of interest to experimenters investigating factors related to computer-assisted learning.

DIALOGUE consists of two independent programs: a presentation module for presenting the different levels of the manipulation (different human-computer dialogues) and collecting various dependent measures, and a data manager module for the examination and modification of collected data. The former interacts with the experiment's subjects; the latter is intended only for use by the experimenter.

\section{Presentation Module}

The presentation module was designed to allow the experimenter to manipulate the style, content, and pacing of the dialogue between the subject and the computer, collect response latencies (in seconds), and record performance data. The experimenter is required to prepare one file or data set for each different dialogue (i.e., set of interactions) with subjects. Each "dialogue file" includes features such as the text of the computer's responses to the user and instructions for branching and pacing, depending upon user reactions. These features are delimited by key-word commands inserted within the dialogue file that are removed from the display during an actual experimental run. These commands can be divided into two general categories: those that control variations in the display and those that control the processing of a quiz. An example of the commands and of a dialogue file as it appears to the experimenter during preparation is depicted in Figure 1.

At the start of an experimental run, the presentation module prompts the experimenter for a group and subject number, which is used to identify each subject's data record. The presentation module then reads the entire dialogue file and stores the text and key-word commands in internal arrays (to avoid variance in diskaccess time from influencing the immediacy of the computer's processing). During the experiment, this information is processed and used to direct both the dialogue and the collection of data. Upon conclusion of the experiment, the presentation module enters a programmed loop, in which the computer does not respond to the subject. The experimenter can exit this loop to start the next subject by entering a password. Password protection also is provided for system initiation to inhibit unauthorized access. To prevent program termination by the subject during the interactive sequence, the module is equipped with terminal control functions that disable "attention interrupts" or break signals.

\section{Data Manager Module}

The second module is a menu-driven data manager program intended for use by the experimenter during the examination or modification of collected data and the on-line monitoring of experiments in progress. The data manager is designed strictly for management of the specially structured subject data file and does not support the creation, display, or modification of the dialogue files. The preparation of the dialogue files is accomplished with the familiar file managers or editors commonly available with most operating systems. An example of the command menu for the data manager and a sample listing of a subject's data are shown in Figure 2.

\section{GENERAL CONSIDERATIONS AND REQUIREMENTS}

DLALOGUE is written in the $\mathrm{PL} / 1$ programming language (for the $\mathrm{PL} / 1$ optimizing compiler) and is implemented on an IBM 370/168 computer in a timesharing (TSO) environment. IBM 3278 video display terminals, hardwired to the computer and capable of 9,600 baud, are used as interactive stations. However, almost any video display terminal can be used as long as the baud rate is high and access to the computer is immediate (phone-access setups are inappropriate). Also, it is necessary in a TSO environment that DIALOGUE be implemented only during periods of low computer usage, since other burdens placed upon the computer may cause the interaction pacing and latency data collection to be inaccurate. DIALOGUE utilizes a 30-track keyed-access (ISAM) disk file to store collected data on subjects. In addition, a one-track, physicalsequential data set stores the text and commands of each different human-computer dialogue. A library of command procedures (CLISTs) aids in the initiation and termination process (allocation and deallocation of required files). DIALOGUE averages $5-10 \mathrm{sec}$ of CPU time in a 1 -h session. Utilization of core is not excessive under TSO.

Our use of DIALOGUE in experiments requires that the experimenter prepare in advance separate dialogue files by means of which the nature of the computer's responses can be systematically varied across groups. The preparation of these files requires repeated pilot testing of the various features to be included at each level of the manipulation. Once completed, these files can be used during an experimental run simply by initiating the presentation module at each terminal, a process that involves entering a unique group and subject number, and providing the subject's first name. There- 


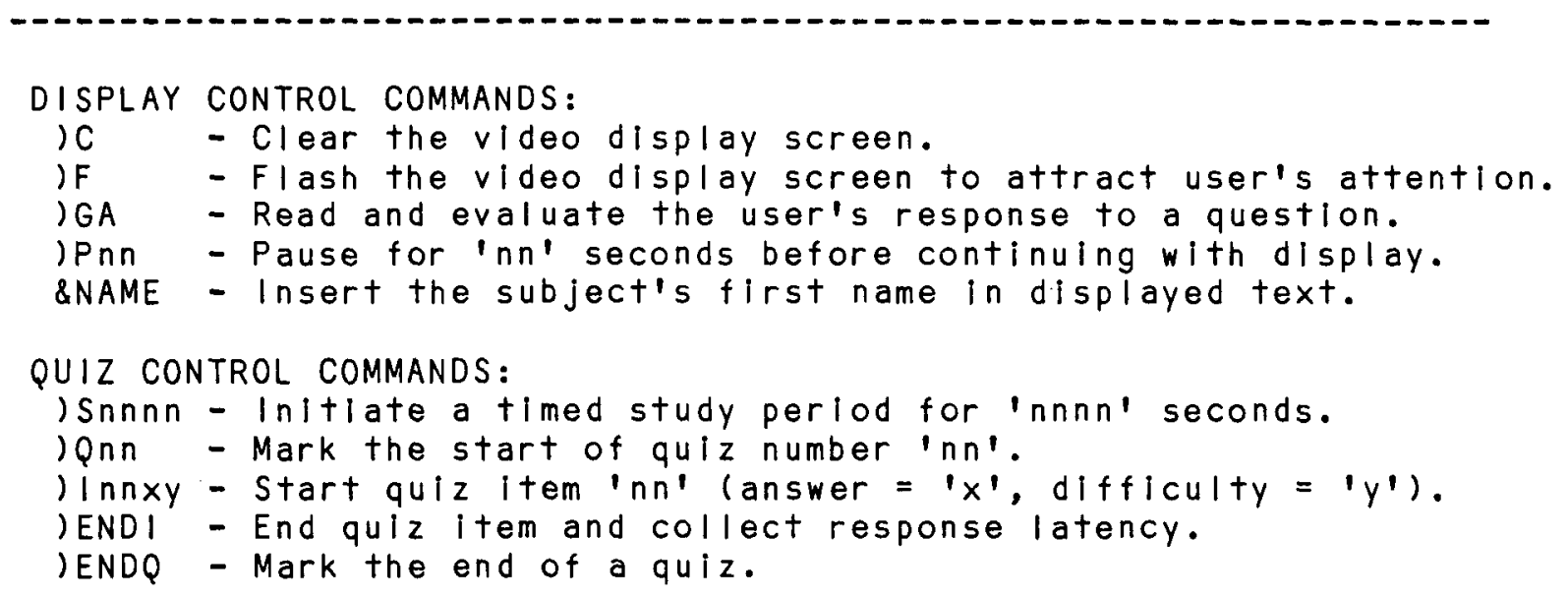

PORTION OF A "DIALOGUE FILE" USING SOME OF THE KEYWORD COMMANDS

WELL, \&NAME...DO YOU UNDERSTAND THE SEQUENCE WE WILL FOLLOW? LGA YES: (If answer is "yes" then show next line and continue)

OK...WE'LL GET STARTED NOW.;

Ne: (If answer is "no" then go back and ask question again)

REALLY? WHY NOT? LOOK OVER MY EXPLANATION AGAIN AND IF YOU STILL DON'T UNDERSTAND, RAISE YOUR HAND, AND ASK FOR HELP.:

S: (if answer is neither "yes" nor "no" then ask question again) PLEASE ANSWER "YES" OR "NO".;

$2 \mathrm{C}$

PLEASE WAIT WHILE I GATHER TOGETHER THE QUIZ QUESTIONS. LPOS

OK, \&NAME, IT'S ALL READY...TAKE A DEEP BREATH...HERE WE GO! LPOL

2001

HERE'S YOUR FIRST QUIZ QUESTION...

$2101 A 3$

IN CLIENT-CENTERED THERAPY, THE THERAPIST

\author{
A. EXPLAINS TO THE CLIENT WHAT HE MUST DO TO OVERCOME HIS \\ PROBLEMS \\ B. LISTENS AND REPEATS ALL OF THE STATEMENTS MADE BY THE \\ CL IENT \\ C. ASKS THE CLIENT A NUMBER OF RELATED QUESTIONS IN ORDER TO \\ FORCE HIM INTO THINKING IN A LOGICAL ORDER \\ LEND」 \\ D. NONE OF THE ABOVE
}

Figure 1. An illustration of the features of the presentation module. The top panel describes a sample of the available keyword commands, whereas the bottom panel depicts a portion of an input "dialogue file" in which these commands may be applied by the experimenter. In the latter, commentary is the lowercase text enclosed in parentheses and all commands (and operands) are underlined. During an actual experimental run, the commands and text are used by the presentation module to direct both the human-computer dialogue and the collection of data. All commands are removed from the text before being displayed to the subject. 


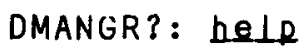

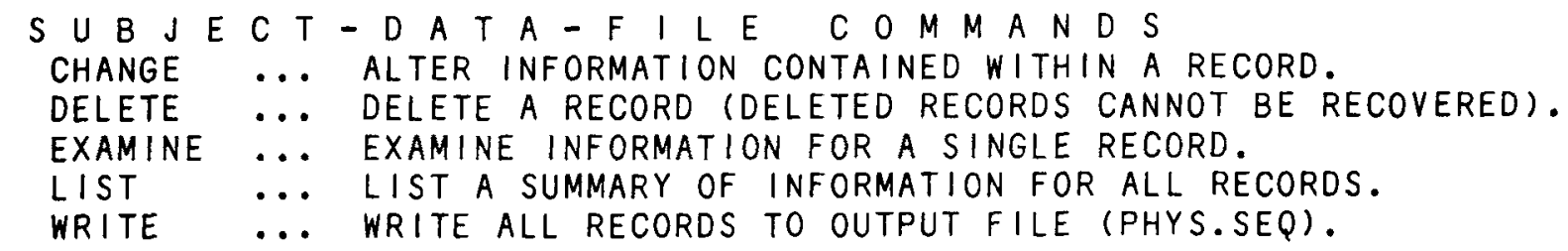

$\begin{array}{ccccc}M \text { I S C E L L A N E O U S C O M M A N D S } \\ \text { END } & \ldots & \text { EXIT FROM DATA MANAGER MODULE. } \\ \text { HELP } & \cdots & \text { DISPLAY THIS COMMAND MENU. } \\ \text { TIME } & \cdots & \text { DISPLAY CURRENT DATE AND TIME. }\end{array}$

DMANGR? : examine

ENTER 4-DIGIT GROUP AND SUBJECT NUMBER COMBINATION: 1101

1 NAME: KATHY 04/01/81 12:08:39 13:25:22 SESSION-LENGTH: 4602

2 TIME SPENT STUDYING FOR RETAKE QUIZ: 1717

$\begin{array}{rrrrrrrrrrrrrrrrrrrrrrr}3 & 1 & 2 & 3 & 4 & 5 & 6 & 7 & 8 & 9 & 10 & 11 & 12 & 13 & 14 & 15 & 16 \\ 4 & 3 & 2 & 3 & 2 & 3 & 2 & 3 & 2 & 3 & 3 & 3 & 2 & 2 & 2 & 2 & 3 \\ 5 & 1 & 0 & 0 & 0 & 0 & 1 & 1 & 0 & 0 & 0 & 1 & 1 & 1 & 1 & 1 & 0 \\ 6 & 49 & 18 & 11 & 18 & 30 & 19 & 64 & 22 & 44 & 20 & 18 & 20 & 28 & 16 & 21 & 18 \\ 7 & 6 & 8 & 7 & 6 & 7 & 4 & 3 & 6 & 4 & 6 & 3 & 2 & 2 & 3 & 2 & 9 \\ & & & & & ( & R & E & T & A & K & E & & Q & U & 1 & Z & 1 & & & \\ 8 & 1 & 2 & 3 & 4 & 5 & 6 & 7 & 8 & 9 & 10 & 11 & 12 & 13 & 14 & 15 & 16 \\ 9 & 3 & 2 & 2 & 3 & 2 & 2 & 2 & 2 & 3 & 2 & 3 & 2 & 3 & 3 & 3 & 3 \\ 10 & 0 & 1 & 0 & 1 & 1 & 1 & 1 & 1 & 0 & 1 & 0 & 1 & 0 & 0 & 1 & 1 \\ 11 & 126 & 14 & 24 & 7 & 8 & 11 & 17 & 98 & 16 & 23 & 11 & 11 & 26 & 44 & 25 & 80 \\ 12 & 7 & 3 & 4 & 4 & 2 & 23 & 7 & 3 & 5 & 2 & 4 & 2 & 6 & 14 & 4 & 5\end{array}$

NOTE: THE DATA LINES UNDER EACH QUIZ DESCRIBE (1) QUESTION NUMBER, (2) ITEM DIFFICULTY LEVEL (3 POINT SCALE), (3) RIGHT/WRONG STATUS, (4) THINK TIME, AND (5) REFLECT TIME.

Figure 2. An example of the command menu for the data manager module and a sample listing of a subject's data from the preliminary experiment. In this and the remaining figures, responses entered by the user are underlined and in lowercase.

after, the experimental procedure is essentially controlled by the dialogue file in effect. Also, in our use of DIALOGUE, each subject is isolated from others (e.g., by screening off the terminal from observation) in order to minimize the possibility that subjects might be exposed, on nearby terminals, to other levels of the manipulation.

The DIALOGUE system is designed for use in a specific remote TSO environment to assist in investigations of human-computer interaction. Therefore, transporting DIALOGUE to other installations with only minimal changes requires an IBM 360 or 370 computer with TSO (or compatible versions) and a PL/1 transient library appropriate for IBM's full implementation of this language. On the other hand, one can view our implementation of DIALOGUE as a guide to the design of similar systems on other computers. Also, it is possible that other installations may already support soft- ware that can serve as a ready basis for the development of a DIALOGUE-like system. For instance, Apple has a good implementation of PILOT with many features that are similar to those of DIALOGUE. Also, certain "authoring systems" used in computer-assisted instruction (e.g., Bell and Howell's GENIS system) may be adapted for this purpose. However, if one is interested, as we were, in the social psychological impact of the "apparent humanness" of the computer's response style, it may be necessary to choose a computer environment in which the subject is not continuously reminded that the computer is a self-contained mechanistic device. Terminals remote from the CPU (and disk drives) may be more efficacious for this purpose than small, easily portable microprocessors, since the latter may inherently supply more cues concerning their machine-like nature. In part, these considerations guided our decision to develop DIALOGUE in the remote TSO environment. 


\section{PRELIMINARY EXPERIMENT}

In an initial investigation, we varied the degree that the interactive computer was perceived to be a "social" stimulus. This manipulation was operationalized by varying the stimulus properties of the computer's responses to the user from human-like to mechanistically nonhuman. Underlying this manipulation was the view that certain social psychological processes would be more strongly evoked by a human-like than a mechanistic computer. The assumption was that these "styles" were at opposite ends of a dimension of judgment. This manipulation was especially interesting in light of the prevalence of interactive programs that present the computer as human-like, that is, as an entity referring to itself as "I" or "me" and displaying simulated intelligent and emotional behavior. For instance, this interactive style can be observed in current computer-assisted instruction software (e.g., the SCHOLAR system, see Rapheal, 1976, and the SOPHIE system, see Hartley, 1980). Since such educational settings are usually characterized by substantially more direct student interaction with the computer than with the course instructor, an investigation of the impact on students of the computer's responses seemed particularly relevant. For this reason, we selected the popular computermanaged instruction context to study the effects of our manipulation.

Two social psychological theories that may be relevant to the possible consequences of a human-like style of computer responses are social facilitation theory (see Geen \& Gange, 1977) and attribution theory (see Kelley \& Michela, 1980). An application of social facilitation theory suggests that the user might view a human-like interactive computer as a potential source of personal evaluation and thereby experience a sense of apprehension and emotional arousal. If this is the case, then the user should exhibit a "socially facilitated" pattern of performance. Such a pattern is normally characterized by the stimulation of dominant behaviors (resulting in especially quick and accurate performance on familiar or easy tasks) and the inhibition of subordinate behaviors (leading to especially slow and inaccurate performance on nonfamiliar or difficult tasks).

The application of attribution theory is suggested by Heider's (1944) conception that persons are more likely to be perceived as causal agents than nonpersons are. Thus, the user may be more likely to view a human-like computer as responsible for events during the interactive sequence. Such changes in the user's feelings of responsibility can be especially important in an educational environment. If the student assumes less personal responsibility for academic success and/or failure as a result of interacting with a human-like (as opposed to a mechanistic) style of computer, then the student may be less motivated to maintain or improve performance during later interactions. Such an expectation follows from Weiner's $(1974,1980)$ recent work on the consequences for achievement motivation of causal attribution (i.e., perceived causality).

In the experiment described here, we explored these possibilities in a computer-managed educational setting under certain conditions in which, initially, the student does less well than is possible. We refer to this less than optimal performance as a "failure" experience. In this context, we attempted to determine the dimensions of judgment underlying perception of interactive computers, how our manipulation of the computer's response style would be reflected in these dimensions, and whether or not such a manipulation would have any effects upon attitude and performance before and after failure.

\section{Method}

Subjects and Design. Twenty-six volunteer undergraduate students served as subjects in a 2 by 2 mixed-factorial design in which the between-subjects factor was the computer's response style (human-like/mechanistic) and the within-subjects factor was quiz (initial/retake). Subjects were assigned randomly to either the human-like or mechanistic style, with the stipulation that subject gender be equated across groups.

Manipulation and Materials. The information input into DIALOGUE for the video-screen display formed the core of the response-style manipulation and was designed and pilot tested to simulate human-likeness in one case, and nonhuman, mechanistic automaticity in the other. As shown in Figure 3, the humanlike style exhibited affective responses, diversity (i.e., variation in responses and pauses), and human-like self-references (i.e., use of the pronouns " $I$ " and "me"). All of these characteristics were arranged in a conversational mode of interaction that involved multiple sentences appropriately linked, complete thoughts, and use of the subject's first name. In contrast, the mechanistic style. depicted in Figure 4, was affectively neutral, repetitive, and impersonal and utilized an outline mode of dialogue that was highly structured and terse. Furthermore, the mechanistic response style reinforced its own mechanistic character by accepting only numbers as answers to its questions. In all other respects, the interaction between the subject and the computer were identical across the two response styles.

The readings and study materials for the experiment were drawn from the final chapter of a general psychology textbook (Lefton, 1979) dealing with the topic of "psychotherapy." A total of 32 quiz questions, distributed over two tests, were selected from a bank supplied by Lefton. Each item had been pretested on college students to establish difficulty. Each of the two 16-item quizzes was constructed to tap the same concepts discussed in the readings (target objectives) while maintaining the same overall level of difficulty (half were moderately difficult and half were very difficult); however, different question items were used on each.

Pre- and postexperiment questionnaires were used to collect additional dependent measurements. The former included 11-point Likert-type rating measures of subjects' prior experience with computers, knowledge of psychology, and initial attitudes toward computers, quiz taking, psychological experiments, and psychotherapy. The postexperiment measures were designed to assess perceived characteristics of the computer (48 bipolar 7-point adjective scales in semantic differential format), perceived causality regarding quiz performance (cf. Meyer, 1980; Pryor \& Kriss, 1977), and included various ancillary Likert-type rating measures that tapped perceived quiz difficulty, suspicion of the experiment, perceived effort, estimated long-term retention, and affect toward the study material, 


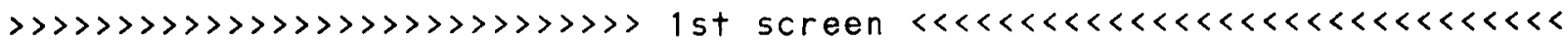

HI THERE, JOHN! \#1\#

IT'S NICE TO MEET YOU. \#1\#

MY NAME IS CARL (SHORT FOR "COMPUTER ASSIST FOR REMOTE LEARNING"). \#1"

I AM BUSY WITH OTHER THINGS RIGHT NOW... \#3\#

PLEASE "RING MY DOORBELL" WHEN YOU ARE READY TO TALK WITH ME... (PRESS THE "ENTER" KEY AT THE LOWER RIGHT CORNER OF THE KEYBOARD):

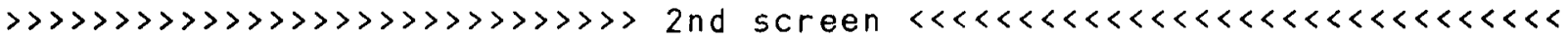

HELLO AGAIN, JOHN. I SEE YOU ARE READY NOW. \#1\#

ACCORDING TO MY RECORDS, YOU ARE ONE OF MY NEW PSYCHOLOGY STUDENTS.

BEFORE WE BEGIN, THERE ARE A FEW POINTS I'D LIKE YOU TO REMEMBER: \#2\#

FIRST, WHENEVER I ASK YOU A QUESTION, PLEASE GIVE ME THE KIND OF ANSWER YOU WOULD ORDINARILY GIVE ANOTHER PERSON. FOR EXAMPLE, IF I ASK "ARE YOU READY TO START STUDYING?" THEN JUST TYPE IN A "YES" OR "NO". \#1"

SECOND, AFTER EVERY ANSWER YOU GIVE ME, YOU MUST PRESS THE "ENTER" KEY. THINK OF THE "ENTER" KEY AS MY "DOORBELL"...WHEN YOU PRESS IT, I AM NOTIFIED THAT YOU HAVE ANSWERED MY QUESTION. \#1 \#

THIRD, IF YOU HAVE ANY PROBLEMS OR DON'T UNDERSTAND SOMETHING THEN PLEASE RAISE YOUR HAND AND THE PERSON-IN-CHARGE WILL GLADLY HELP. \#1 \#

DO YOU THINK YOU UNDERSTAND THESE THREE POINTS?: ¥ES

FINE. AS YOU'LL SEE, THESE RULES WILL BE USEFUL. \#2\#

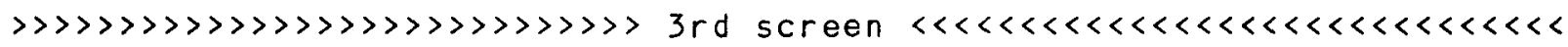

SINCE YOU ARE NEW TO THIS SORT OF THING, I WOULD LIKE TO TAKE A LITTLE BIT OF TIME TO INTRODUCE A FEW THINGS TO YOU, JOHN. PLEASE READ ALL MY MESSAGES CAREFULLY. \#3\#

FIRST OF ALL, THE WORD "TERMINAL" IS THE TERM USED TO DESCRIBE THE VIDEO SCREEN AND KEYBOARD DEVICE THAT IS DIRECTLY IN FRONT OF YOU. \# 1 \# THE TERMINAL IS USED TO TALK WITH ME FROM A DISTANCE (I AM ACTUALLY LOCATED CLEAR ACROSS CAMPUS NEAR THE MEMOR (AL LIBRARY)...AND IN THIS RESPECT, THE TERMINAL FUNCTIONS JUST LIKE A FANCY "VIDEO TELEPHONE"! \#1"

UNFORTUNATELY, THE TERMINAL IS JUST A DUMB MACHINE (UNLIKE YOU AND ME) AND THIS PLACES SOME RESTRICTIONS UPON OUR COMMUNICATION. YOU'VE ALREADY LEARNED ABOUT ONE OF THESE RESTRICTIONS ...PRESSING THE "ENTER" KEY AFTER ANSWERING MY QUESTIONS. ACTUALLY, THE TERMINAL DOESN'T EVEN SEND ME YOUR MESSAGE UNTIL YOU PRESS THE "ENTER" KEY! \#1

DO YOU UNDERSTAND WHAT A TERMINAL IS?: \ES

OK, NOW...LET ME SEE WHAT'S NEXT ON MY AGENDA FOR NEW STUDENTS. \#2\#

Figure 3. An illustration of the human-like style of computer responses as seen by subjects in the preliminary experiment. The first three video display screens of human-computer dialogue are presented. In this and the remaining figures, numbers bracketed by the "\#" symbol were not shown but, rather, indicate the number of seconds that the computer momentarily paused at this point in the display. (Compare with Figure 4.) 


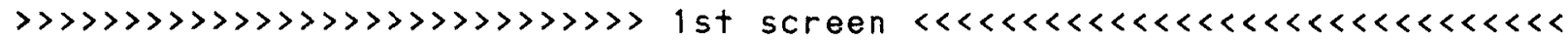
********************************************************************* * M E C H A N I C A L T E A C H I N G - A I D $\left(\begin{array}{llllllll}1 & B & M & -3 & 7 & 0\end{array}\right) *$

*********************************************************************

THE MECHANICAL TEACHING-AID (M.T.A) IS AN IBM-370 COMPUTER WHICH HAS BEEN PROGRAMMED TO ASSIST STUDENTS DURING STUDY-PERIODS AND QUIZZES ("IBM" IS AN ABBREVIATION FOR "INTERNATIONAL BUSINESS MACHINES, INC" AND "370" IS THE MODEL NUMBER IDENTIFYING THIS TYPE OF MACHINE).

M.T.A. IS PRESENTLY IN A "WAIT STATE" AND WILL BECOME ACTIVE WHEN THE "ENTER" KEY (LOCATED AT LOWER RIGHT CORNER OF KEYBOARD) IS PRESSED. \#6\#

PRESS THE "ENTER" KEY TO BEGIN SESSION $\Rightarrow$ :

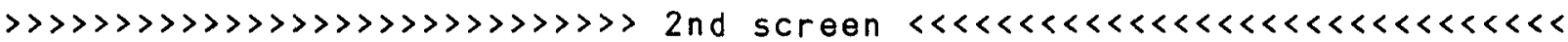
MECHANICAL TEACHING-A|D (|BM-370)

YOU HAVE BEEN ASSIGNED THE FOLLOWING STUDENT NUMBER $=\Rightarrow 23$

THE FOLLOWING NAME HAS BEEN ASSOCIATED WITH NUMBER $==>$ JOHN

RULES FOR COMMUNICATING WITH IBM-370:

1. ANSWER ALL QUESTIONS (EXCEPT QUIZ ITEMS) WITH A SINGLE NUMBER (EXAMPLE: $1=$ YES, $2=$ NO).

2. ANSWER QUIZ ITEMS (MULTIPLE CHOICE) WITH A SINGLE LETTER $(A, B, C, D)$.

3. PRESS "ENTER" KEY AFTER EVERY ANSWER YOU TYPE (THE "ENTER" KEY TRANSMITS THE ANSWER TO THE IBM-370 FOR (MMEDIATE PROCESSING).

4. RAISE YOUR HAND AND ASK PERSON-IN-CHARGE IF YOU HAVE PROBLEMS. \#6\#

WOULD YOU LIKE RULES REPEATED? $(1=$ YES, $2=N O) \Rightarrow: 2$ **PROCESSING** \#2\#

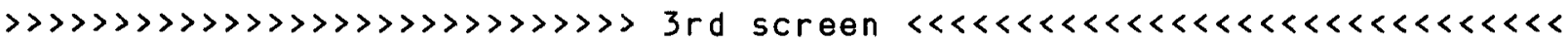
MECHANICAL TEACHING-A|D (IBM-370)

SCAN OF FILE FOR STUDENT 23 INDICATES THE FOLLOWING INFORMATION:

1. COURSE TOPIC FOR STUDENT $=====\Rightarrow$ PSYCHOLOGY

2. \# OF PREVIOUS QUIZZES $===== \pm 0$

3. STUDENT'S COURSE STATUS $======>$ NEW

NEW STUDENTS ARE REQUIRED TO RECEIVE AN INTRODUCTION TO M.T.A. SYSTEM BEFORE SESSION CAN FORMALLY BEGIN. PLEASE READ EVERYTHING CAREFULLY.

INTRODUCTION :

A "COMPUTER TERMINAL" IS THE VIDEO-SCREEN AND KEYBOARD DEVICE THAT IS DIRECTLY IN FRONT OF YOU. TERMINALS ARE USED BY PEOPLE TO INTERACT WITH AND GIVE COMMANDS TO COMPUTERS FROM A DISTANCE. SEVERAL OF THE FOLLOWING PAGES OF THE INTRODUCTION EXPLAIN HOW TO USE THE TERMINAL EFFECTIVELY. \#6\#

DO YOU UNDERSTAND WHAT A TERMINAL IS? $(1=Y$ YE, $2=N O) \Rightarrow: 1$ **AFFIRMATION REGISTERED** \#2\#

Figure 4. An illustration of the mechanistic nonhuman-like style of computer responses as seen by subjects in the preliminary experiment. (Compare with Figure 3.) 
the computer, and computer-managed instruction. The effectiveness of our attempt to maintain equality of the experimental groups on dimensions outside the response-style manipulation was assessed by rating the degree of understandability of the computer's behavior and the degree of affect experienced when the computer presented positive or negative leedback. Thought listings (Cacioppo \& Petty, 1981) about the computer were collected in the first part of the postexperiment questionnaire.

Procedure. Upon arrival, subjects were told that the purpose of the experiment was to explore the various learning and memory processes involved during quiz taking and studying but "to make the evaluation and scoring of your quizzes easier, we would like you to take them with the university computer." At this time, subjects completed the preexperiment questionnaire.

Subjects were assigned to a computer terminal that was screened off from observation by other subjects. The experimenter then entered each subject's first name at his terminal and explained that all instructions were to be given by the computer.

At this point, the subject's session with the computer began and consisted of (1) an introduction to the computer and instructions regarding the use of the terminal, (2) a description of the session sequence, (3) a limited (17-min) study period to prepare for the initial quiz, (4) an initial quiz over the written study material that inevitably led to a "failure" experience, (5) an unrestricted study period (up to $1 \mathrm{~h}$ ) for the same material to prepare for the retake quiz, and (6) a retake quiz. The initial study period was selected in order to insure that subjects would not have enough time to cover the study material so thoroughly as to obtain a high score on the initial quiz, and yct to provide sufficient time to minimize the attribution of failure to an insufficient opportunity to study the material. Pilot research suggested that $17 \mathrm{~min}$ provided the best balance between these two objectives. DIALOGUE timed the study period and signaled the period's conclusion by rapid flashes upon the video screen. Quiz questions were presented one at a time, and subjects were given immediate feedback on the correctness of each answer. In light of this feedback, subjects could reflect upon the question and answer (which remained on the video screen) before moving to the next question.

DIALOGUE also collected a variety of performance measures, including (1) the quiz scores, (2) the time (in seconds) spent thinking and reading each question before answering, (3) the time (in seconds) spent reflecting upon each question after receiving feedback and before moving to the next question, (4) the time (in seconds) spent studying for the retake quiz, and (5) the frequency of simple response errors, such as entering an " $A$ " character when instructed to enter a blank line.

Upon conclusion of the session, subjects completed the postexperiment questionnaire and were debriefed.

\section{Results and Discussion}

There are three central aspects of the results: the subjects' perceptions of the interactive computer, the factors to which subjects attributed their quiz performance, and the objective measures of a subject's quiz performance.

Perceptions of the computer. The results of an analysis of variance (ANOVA) on bipolar ratings for a human-like/mechanistic scale indicated that the computer was appropriately perceived as human-like or mechanistic by subjects in the respective experimental conditions $[F(1,24)=12.52, p<.01]$. This finding provides a check on our manipulation of the computer's response style. To determine the judgmental dimensions underlying perception of the different styles of computer, a combined-group factor analysis was performed on all 48 adjective scales regarding perceived characteristics of the computer. A principal-components analysis with varimax rotation was employed (see Kim \& Mueller, 1978). The number of factors retained was decided by the solution that best satisfied the following criteria: the size of the eigen-value differences between factors, the percentage of variance explained, the meaningfulness of the factor structures resulting from each of the pussible rotations. the perseverance of factors over different rotations, the number of high loadings on each factor, and the outcome of a modified scree test. As shown in Table 1, we selected a rotation of four factors accounting for $53.8 \%$ of the variance as representing a best estimate of the judgmental dimensions underlying the perception of interactive computers. These factors were humanness, courtesy, incongruity, and honesty, respectively.

To assess the differences in subjects' perceptions of the computer resulting from our response-style manipulation, a discriminant analysis was performed upon the scores derived from the four factors. A significant discrimination between the groups was obtained $\left[\chi^{2}(4)=\right.$ 13.68, $\mathrm{p}<.01$; canonical correlation $=.68]$. Total structure coefficients (Klecka, 1980), along with standardized coefficients, were then calculated and are shown in Table 2. The human-like style was seen as more human, less honest, and slightly less courteous than the mechanistic style of computer (group means on the discriminant function were .89 and -.89 , respectively).

Other analyses revealed that subjects listed greater numbers of thoughts and had lower percentages of neutral thoughts about the computer with a humanlike than with a mechanistic response style $[F(1,24)=$ $7.11, p<.05$, and $F(1,24)=4.79, p<.05$, respectively]. However, subjects in the two experimental conditions did not differ with respect to such ancillary dimensions as enjoyment of the interaction with the computer, understandability of the computer's messages, degree of reported affect aroused by positive/negative comments from the computer, attitude toward computermanaged instruction, or prior computer experience. There also was no difference in the suspicion that the "interaction with a computer" was a sham (i.e., suspicion that the messages received upon the terminal's video screen were not from a computer, but from a hidden person). The absence of a suspicion difference and the fact that the overall mean suspicion rating was low (mean $=2.58)$ indicates that subjects believed that they were reacting to a computer.

Perceptions of the causes of quiz performance. As expected, subjects rated (on the postexperiment questionnaire) their performance on the initial quiz as a relative failure, whereas they regarded their retake performance as a relative success $[\mathrm{F}(1,24)=34.90$, $\mathrm{p}<.001]$. Results of analyses upon a wide variety of 
Table 1

Rating Scales and Factor Loadings for Perceived Characteristics of the Computer

\begin{tabular}{|c|c|c|c|c|c|}
\hline \multicolumn{2}{|c|}{ Bipolar Adjective Scale } & \multirow{3}{*}{$\begin{array}{r}\text { Factor } 1 \\
(27.5 \%) \\
-.88^{*}\end{array}$} & \multirow{2}{*}{$\begin{array}{c}\text { Factor } 2 \\
(10.2 \%)\end{array}$} & \multirow{2}{*}{$\begin{array}{c}\text { Factor } 3 \\
(9.1 \%)\end{array}$} & \multirow{2}{*}{$\begin{array}{c}\text { Factor } 4 \\
(6.9 \%)\end{array}$} \\
\hline$(+)$ & $(-)$ & & & & \\
\hline Impersonal & Personal & & -.03 & -.05 & .13 \\
\hline Human-Like & Mechanistic & $.81^{*}$ & .11 & .02 & -.12 \\
\hline Unintelligent & Intelligent & -.24 & -.25 & $.59^{*}$ & -.02 \\
\hline Friendly & Unfriendly & $.71^{*}$ & .49 & -.02 & -.11 \\
\hline Alert & Inattentive & .35 & .36 & -.40 & .05 \\
\hline Cold & Warm & $-.71^{*}$ & -.13 & .02 & .13 \\
\hline Thoughtless & Thoughtful & -.44 & $-.73 *$ & .15 & .15 \\
\hline Close-Minded & Open-Minded & .02 & -.32 & .47 & .25 \\
\hline Emotional & Unemotional & $.73 *$ & .32 & -.14 & -.03 \\
\hline Uncomprehending & Comprehending & -.12 & -.06 & $.71^{*}$ & -.35 \\
\hline Alive & Dead & $.68^{*}$ & .34 & -.13 & -.39 \\
\hline Conscious & Unconscious & $.70^{*}$ & .28 & -.27 & -.26 \\
\hline Constrained & Free & $-.54^{*}$ & .01 & .33 & .32 \\
\hline Illogical & Logical & .05 & -.15 & $.71^{*}$ & .04 \\
\hline Nonsexual & Sexual & -.01 & -.10 & $-.63^{*}$ & .25 \\
\hline Unaware & Aware & $-.67^{*}$ & .12 & .33 & -.16 \\
\hline Sincere & Insincere & $.54^{*}$ & .26 & -.00 & .28 \\
\hline Passive & Active & $-.60^{*}$ & .42 & .35 & -.04 \\
\hline Weak & Strong & .20 & -.08 & .17 & -.44 \\
\hline Decisive & Indecisive & .35 & .29 & -.47 & .29 \\
\hline $\mathrm{Bad}$ & Good & $-.56^{*}$ & -.38 & .05 & -.20 \\
\hline Irresponsible & Responsible & .06 & -.36 & .07 & .01 \\
\hline Efficient & Inefficient & .04 & -.06 & -.11 & .40 \\
\hline Selfish & Unselfish & .33 & $-.67^{*}$ & .17 & -.16 \\
\hline Impolite & Polite & -.21 & $-.74^{*}$ & .08 & -.17 \\
\hline Rational & Irrational & .21 & $.62 *$ & -.29 & -.01 \\
\hline Likable & Unlikable & $.64^{*}$ & $.53^{*}$ & -.03 & .16 \\
\hline Moral & Immoral & -.14 & .30 & .33 & .19 \\
\hline Immature & Mature & -.48 & -.04 & .09 & -.19 \\
\hline Sociable & Unsociable & $.72 *$ & .19 & .11 & -.02 \\
\hline Dependent & Independent & -.47 & .19 & .07 & .07 \\
\hline Fair & Unfair & .11 & .45 & -.31 & $.60^{*}$ \\
\hline Phony & Authentic & -.02 & $-.68^{*}$ & -.10 & -.46 \\
\hline Humorless & Humorous & $-.50^{*}$ & -.18 & $-.57 *$ & -.40 \\
\hline Inoffensive & Offensive & .12 & $.67 *$ & -.32 & .07 \\
\hline Uninteresting & Interesting & $-.54 *$ & $-.53^{*}$ & -.11 & -.20 \\
\hline Obedient & Disobedient & -.40 & .12 & .17 & $.55^{*}$ \\
\hline Uneducated & Educated & $-.50^{*}$ & -.02 & .03 & -.41 \\
\hline Honest & Dishonest & .10 & .18 & .01 & $.77^{*}$ \\
\hline Deep & Superficial & .42 & $.61^{*}$ & .06 & -.06 \\
\hline Unpleasant & Pleasant & $-.73^{*}$ & -.32 & -.07 & -.41 \\
\hline Creative & Uncreative & $.68^{*}$ & .12 & .39 & .36 \\
\hline Reliable & Unreliable & .17 & .00 & .16 & $.65^{*}$ \\
\hline Sensitive & Insensitive & .47 & $.66^{*}$ & .32 & .05 \\
\hline Unkind & Kind & -.44 & $-.55^{*}$ & -.09 & .25 \\
\hline Undemanding & Demanding & .29 & .37 & .05 & .18 \\
\hline Inaccurate & Accurate & .02 & -.03 & $.65^{*}$ & -.04 \\
\hline Prejudiced & Unprejudiced & .07 & -.00 & .08 & -.43 \\
\hline
\end{tabular}

Note-Positive loadings indicate a high score toward the first pole of the bipolar scales (and vice versa for negative loadings). Beneath each factor's heading is the percentage of explained variance prior to varimax rotation. $\quad *$ Loading $\geqslant .50$.

causal attribution scales indicated, in general, that subjects blamed perceived failure on the initial quiz on insufficient study time. Also, factors influencing the retake quiz appeared less detrimental to performance than those affecting the initial quiz. When only attributions to the self and the computer were compared, performance on both quizzes was perceived to be more a function of the former than the latter factor. However, planned comparisons of groups using only the attribution scale regarding the causal influence of the computer marginally supported the prediction that the humanlike style was perceived as more responsible for the user's quiz performance than the mechanistic style [for initial, $\mathrm{t}(24)=1.83, \mathrm{p}<.05$; for retake, $\mathrm{t}(24)=$ $1.89, \mathrm{p}<.05$; one-tailed tests). Thus, although subjects generally considered themselves more responsible for their performance than the computer, the level of attribution directed to the computer was somewhat greater under the human-like than under the mechanistic response style. 
Table 2

Discriminant Function for Perception of the Computer

\begin{tabular}{ccc}
$\begin{array}{c}\text { Factor Score } \\
\text { Variable }\end{array}$ & $\begin{array}{c}\text { Standardized } \\
\text { Coefficient }\end{array}$ & $\begin{array}{c}\text { Structure } \\
\text { Coefficient }\end{array}$ \\
\hline Factor 1 & .81 & $.80 \dagger$ \\
Factor 2 & -.19 & $.33^{*}$ \\
Factor 3 & .63 & .12 \\
Factor 4 & -.62 & $-.66 \dagger$ \\
\hline
\end{tabular}

$*_{p}<.10 . \quad t_{p}<.01$.

The groups also differed in perceived influence of the experimenter's biases (e.g., likes and dislikes). Subjects felt that these biases helped quiz performance under a human-like style and had little influence under a mechanistic style of computer [for initial and retake, $F(1,24)=4.15, p<.05]$. Although the experimenter was careful to avoid actual bias, any possible social facilitation effects provoked by the human-like style of computer could have made it more likely that subjects would perceive the experimenter as exerting a greater influence on their performance.

Quiz performance. Separate multivariate ANOVAs were applied to the quiz score and response latency measures for each quiz, and an overall multivariate ANOVA was used for the combined measures of both quizzes. Results revealed that groups were significantly different on each analysis $[F(2,23)=4.43, p<.02$, $F(2,23)=4.43, p<.02$, and $F(4,21)=3.64, p<.02$, respectively]. The pattern of results on the univariate ANOVAs indicated that the human-like style of computer induced subjects to score higher on both quizzes and to spend more time thinking about each question before answering, as well as reflecting when an answer was scored as incorrect. Separate analyses of the moderate or difficult items revealed a pattern of effects similar to these overall results. These performance differences were constant on both quizzes, even though groups did not differ in the amount of time spent studying for the retake, and even though all subjects tended to improve their quiz scores on the retake $[F(1,24)=43.61$, $\mathrm{p}<.001]$.

\section{CONCLUSIONS}

The results suggest that subjects perceived an interactive computer to exhibit characteristics along dimensions of humanness, courtesy, incongruity, and honesty. A manipulation of the computer's response style was found primarily to affect the humanness and honesty dimensions. Interestingly, the more human-like computer was perceived to be the less honest. Possibly, this finding is a reflection of a general tendency to associate a mechanistic and automatic nature with greater objectivity and less bias than a human or human-like nature.
Also, there was some evidence that users perceive the computer as more responsible for their performance under a human-like as compared with a mechanistic response style. This finding could be viewed as consistent with the previously noted tendency of subjects in our study to view the human-like computer as less honest. Perhaps this outcome is analogous to the complaint often mentioned by students that poor performance must be a reflection of unfair exam practices.

Despite viewing the human-like computer as less honest. subjects exposed to this style also performed better on quizzes and expended greater amounts of time thinking about and reflecting upon quiz items. This outcome may be an indication of a social facilitationlike effect with the human-like response style, although such an effect was not differential across the disparate levels of quiz-item difficulty. Apparently, what is involved is a tradeoff between higher quiz scores on the one hand and more favorable perceptions on the other.

Even though our manipulations evoked differences in perceptions and performance, we are somewhat tentative about the specific nature of the social psychological processes operative under a human-like interactive computer. For instance, the attribution hypothesis may not have been adequately tested because causal attributions with respect to quiz performance were absorbed primarily by the initial study-time constraint. Thus, any motivational consequences resulting from attribution to the computer may not have had a chance to develop fully. And the social facilitation hypothesis may not have been clearly tested either, because measurements of evaluation apprehension and test anxiety were not included and the range of quiz question difficulty was limited to difficult/moderate items. Accordingly, the present study must be regarded as preliminary but suggestive of the potential importance of the interactive computer viewed as a social stimulus.

\section{REFERENCES}

Allpont, G. The historical background of modern social psychology. In G. Lindzey \& E. Aronson (Eds.), The handbook of social psychology (2nd ed., Vol. 1). Reading, Mass: AddisonWesley, 1968.

Cacroppo, J. T., \& Petry, R. E. Social psychological procedures for cognitive response assessment: The thought-listing technique. In T. V. Merluzzi, C. R. Glass, \& M. Genest (Eds.), Cognitive assessment. New York: Guilford Press, 1981.

GeEn, R. G., \& GAnge, J. J. Drive theory of social facilitation: Twelve years of theory and research. Psychological Bulletin, $1977,84,1267-1288$.

Hartley, J. R. Computer-assisted learning. In H. T. Smith \& T. R. G. Green (Eds.), Human interaction with computers. New York: Academic Press, 1980.

Heider, F. Social perception and phenomenal causality. Psychological Review, 1944, 51, 358-374.

Kelley, H. H., \& Michela, J. L. Attribution theory and research. Annual Review of Psychology, 1980, 31, 457-501.

Kıм, J., \& Mueller, C. W. Factor analysis: Statistical methods and practical issues (Sage University Paper Series on Quanti- 
tative Applications in the Social Sciences, 07-014). Beverly Hills, Calif: Sage Publications, 1978.

KleckA, W. R. Discriminant analysis (Sage University Paper Series on Quantitative Applications in the Social Sciences, 07019). Beverly Hills, Calif: Sage Publications, 1980.

Lefton, L. A. Psychology. Boston: Allyn \& Bacon, 1979.

Meyer, J. P. Causal attribution for success and failure: A multivariate investigation of dimensionality, formation, and consequences. Journal of Personality and Social Psychology, 1980, 38, 704-718.

PRYOR, J. B., \& KRISS, M. The cognitive dynamics of salience in the attribution process. Journal of Personality and Social Psychology, 1977, 35, 49-55.
RAPHEAL, B. The thinking computer. San Francisco: Freeman, 1976. Shneiderman, B. Software psychology: Human factors in computers and information systems. Cambridge, Mass: Winthrop, 1980.

Smith, H. T., \& Green, T. R. G. (Eds.), Human interaction with computers. New York: Academic Press, 1980.

WEINER, B. An attributional interpretation of expectancy-value theory. In B. Weiner (Ed.), Cognitive views of human motivation. San Francisco: Academic Press, 1974.

Weiner, B. Human motivation. New York: Holt, Rinehart \& Winston, 1980.

Weizenbaum, J. Computer power and human reason. San Francisco: Freeman, 1976. 